\title{
Remifentanil Protects Myocardium through Activation of Anti- Apoptotic Pathways of Survival in Ischemia-Reperfused Rat Heart
}

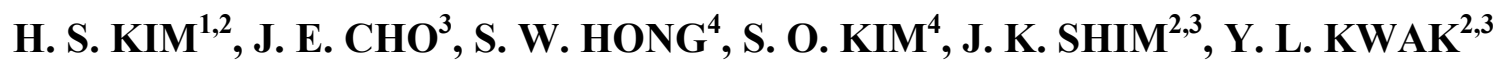 \\ ${ }^{1}$ Brain Korea 21 Project for Medical Science, ${ }^{2}$ Anesthesia and Pain Research Institute and \\ ${ }^{3}$ Department of Anesthesiology and Pain Medicine, Yonsei University College of Medicine, Seoul, \\ Republic of Korea, ${ }^{4}$ Department of Anesthesiology and Pain Medicine, Kyungpook National \\ University, Daegu, Republic of Korea
}

Received February 23, 2009

Accepted July 31, 2009

On-line August 12, 2009

\section{Summary}

Remifentanil is a commonly used opioid in anesthesia with cardioprotective effect in ischemia-reperfused (I/R) heart. We evaluated the influence of remifentanil on myocardial infarct size and expressions of proteins involved in apoptosis in $\mathrm{I} / \mathrm{R}$ rat heart following various time protocols of remifentanil administration. Artificially ventilated anesthetized Sprague-Dawley rats were subjected to a $30 \mathrm{~min}$ of left anterior descending coronary artery occlusion followed by $2 \mathrm{~h}$ of reperfusion. Rats were randomly assigned to one of five groups; Sham, I/R only, remifentanil preconditioning, postconditioning and continuous infusion group. Myocardial infarct size, the phosphorylation of ERK1/2, Bcl2, Bax and cytochrome $\mathrm{c}$ and the expression of genes influencing $\mathrm{Ca}^{2+}$ homeostasis were assessed. In remifentanil-administered rat hearts, regardless of the timing and duration of administration, infarct size was consistently reduced compared to I/R only rats. Remifentanil improved expression of ERK $1 / 2$ and anti-apoptotic protein $\mathrm{BCl} 2$, and expression of sarcoplasmic reticulum genes which were significantly reduced in the $I / R$ rats only. Remifentanil reduced expression of pro-apoptotic protein, Bax and cytochrome c. These suggested that remifentanil produced cardioprotective effect by preserving the expression of proteins involved in anti-apoptotic pathways, and the expression of sarcoplasmic reticulum genes in $I / R$ rat heart, regardless of the timing of administration.

\section{Key words}

Anti-apoptosis • Cardioprotection • Ischemia/ reperfusion injury • Remifentanil

\section{Corresponding author}

Y. L. Kwak, Department of Anesthesiology and Pain Medicine, Anesthesia and Pain Research Institute, Yonsei University College of Medicine, 134 Shinchon-Dong, Seodaemun-Ku, Seoul 120-752, Republic of Korea. Fax: +82 2364 2951. E-mail: ylkwak@yuhs.ac

\section{Introduction}

Despite restoration of coronary blood flow, ischemia-reperfusion ( $\mathrm{I} / \mathrm{R})$ injury in myocardium triggers stress signaling processes that eventually result in various degree of myocardial damage (Anaya-Prado et al. 2002, Fliss and Gattinger 1996). In attempts to lessen the I/R injury, ischemic preconditioning was introduced as an effective treatment modality (Murry et al. 1986). Certain anesthetic agents also possess cardioprotective effects against I/R injury, mimicking ischemic preconditioning, termed pharmacological preconditioning (Schultz and Gross 2001, Tanaka et al. 2004). Remifentanil, is an ultra-short-acting, selective, $\mu$-opioid receptor agonist, gaining increasing popularity in cardiac anesthesia (Glass 1995, Patel and Spencer 1996). Like several anesthetics, remifentanil was reported to protect myocardium against $\mathrm{I} / \mathrm{R}$ injury. In the light of remifentanil's preconditioning effect, the activation of opioid receptors (Peart et al. 2005, Yu et al. 2007, Zhang et al. 2004), protein kinase C (PKC) and mitochondrial adenosine triphosphatesensitive potassium $\left(\mathrm{K}_{\mathrm{ATP}}\right)$ channels were reported to be important mediators of its cardioprotective action (Zhang et al. 2005), although those were observed at doses much 
higher than doses used in clinical practice.

Apoptosis, a programmed cell death, contributes significantly to post-ischemic cardiomyocyte death, (Gottlieb and Engler 1999) but evidence is lacking regarding the effect of remifentanil on anti-apoptotic pathways of survival in $\mathrm{I} / \mathrm{R}$ injury. In mammalian cells, among three major mitogen-activated protein kinases (MAPKs) signaling pathways, activation of extracellular signal related protein kinases (ERK1/2) exerts beneficial effect on post-ischemic myocardial apoptosis (Yue et al. 2000).

Thus, we evaluated the effects of the minimal concentration of remifentanil (Yu et al. 2007, Zhang et al. 2005) against $\mathrm{I} / \mathrm{R}$ injury on myocardial infarction in rat in terms of the expression of proteins involved in apoptosis signaling cascades including ERK1/2 following various time protocols of remifentanil administration in rat heart. In addition, since the proteins involved in apoptosis significantly affect $\mathrm{Ca}^{2+}$ homeostasis, we concomitantly measured expressions of genes associated with $\mathrm{Ca}^{2+}$ homeostasis.

\section{Methods}

Animals

Male Sprague-Dawley rats (250-300 g) were anesthetized with a single i.p. injection of pentobarbital $60 \mathrm{mg} / \mathrm{kg}$ (Yu et al. 2007, Zhang et al. 2004). Anesthesia was maintained by repeated doses of pentobarbital $25 \mathrm{mg}$ $\mathrm{kg}^{-1}$ every 60-90 min. After tracheal intubation, the rats were artificially ventilated (Harvard Apparatus 683, USA) at a rate of 30-35 cycles per minute with oxygen $100 \%$ and a tidal volume of approximately $5 \mathrm{ml}$. The respiratory rate was varied to maintain the end-tidal $\mathrm{CO}_{2}$ by $30-35 \mathrm{~mm} \mathrm{Hg}$ using a capnograph (Datec, Normocap ${ }^{\circledR}$, Finland).

The right femoral artery was used for monitoring of mean arterial pressure, and the heart rate was monitored via subcutaneous stainless steel electrodes. These were connected to a PowerLab monitoring system (ML845 PowerLab with ML132; AD Instruments, USA). The left femoral vein was cannulated to infuse remifentanil or saline. Rectal temperature was maintained at $38^{\circ} \mathrm{C}$ during the entire experiment. The animal experimental procedures were approved by the committee for the Care and Use of Laboratory Animals of our hospital and were performed in accordance with the Committee's Guidelines and Regulations for Animal Care.

\section{Experimental protocol}

After a left thoracotomy and pericardiotomy, the heart was exposed and a suture was passed around the left anterior descending (LAD) coronary artery by inserting a small curved Prolene 6.0 needle into the margin of the pulmonary cone, exiting through the middle of a line linking the cone to the atrium. The suture ends were threaded through a small vinyl tube to prepare a snare. After surgical preparation, the rat was allowed to stabilize for $20 \mathrm{~min}$. In all groups, the LAD coronary artery was occluded for $30 \mathrm{~min}$ by tightening the snare. Myocardial ischemia was confirmed by the appearance of a regional cyanosis on the epicardium distal to the snare and akinesia or bulging in this area. After $30 \mathrm{~min}$ of ischemia, the snare was released and reperfusion allowed for a period of $2 \mathrm{~h}$. Hemodynamic parameters were measured at following time points; 1) at the end of stabilization before ischemia (baseline), 2) at the end of ischemia (or no ischemia), and 3 ) after $2 \mathrm{~h}$ of reperfusion (Fig. 1).

\section{Study groups}

This study consisted of five series of experiments. ' $\mathrm{I} / \mathrm{R}$ ': rats did not receive any remifentanil (Ultiva $^{\mathrm{TM}}$, GlaxoSminthKline, Italy) treatment during the entire experiment $(n=7)$; 'Remifentanil-preconditioning (Pre-R)': rats were subjected to infusion of remifentanil (6 $\mu \mathrm{g} \mathrm{kg}^{-1} \mathrm{~min}^{-1}$ ) during $20 \mathrm{~min}$ before $30 \mathrm{~min}$ of occlusion followed by $10 \mathrm{~min}$ washout $(n=6)$; 'Remifentanil-postconditioning (Post-R)': remifentanil was administered during the first $20 \mathrm{~min}$ of reperfusion ( $n=7)$; 'Long-R': remifentanil was administered from $30 \mathrm{~min}$ before ischemia to the first $20 \mathrm{~min}$ of reperfusion $(n=9)$. Control sham-operated rats (Sham) were treated similarly, except that the coronary suture was not tied, and remifentanil was not administered $(n=5)$.

\section{Infarct size measurement}

At the end of the reperfusion period $(2 \mathrm{~h})$, the heart was excised and immersed in $2 \%$ triphenyltetrazolium chloride (TTC) (Sigma, USA) stain for $20 \mathrm{~min}$ at $37^{\circ} \mathrm{C}$. The infarct myocardium, which does not take up TTC stain when the dehydrogenase enzymes are drained off, remains pale in color. The heart was sliced and photographed, and infarct size was determined by dividing the total necrotic area of the left ventricle (LV) by the total LV area (Kang et al. 2006, Hwang et al. 2004, Gnecchi et al. 2006). The boundary of unstained area was traced in a blinded fashion and quantified with NIH image, version 1.61. 


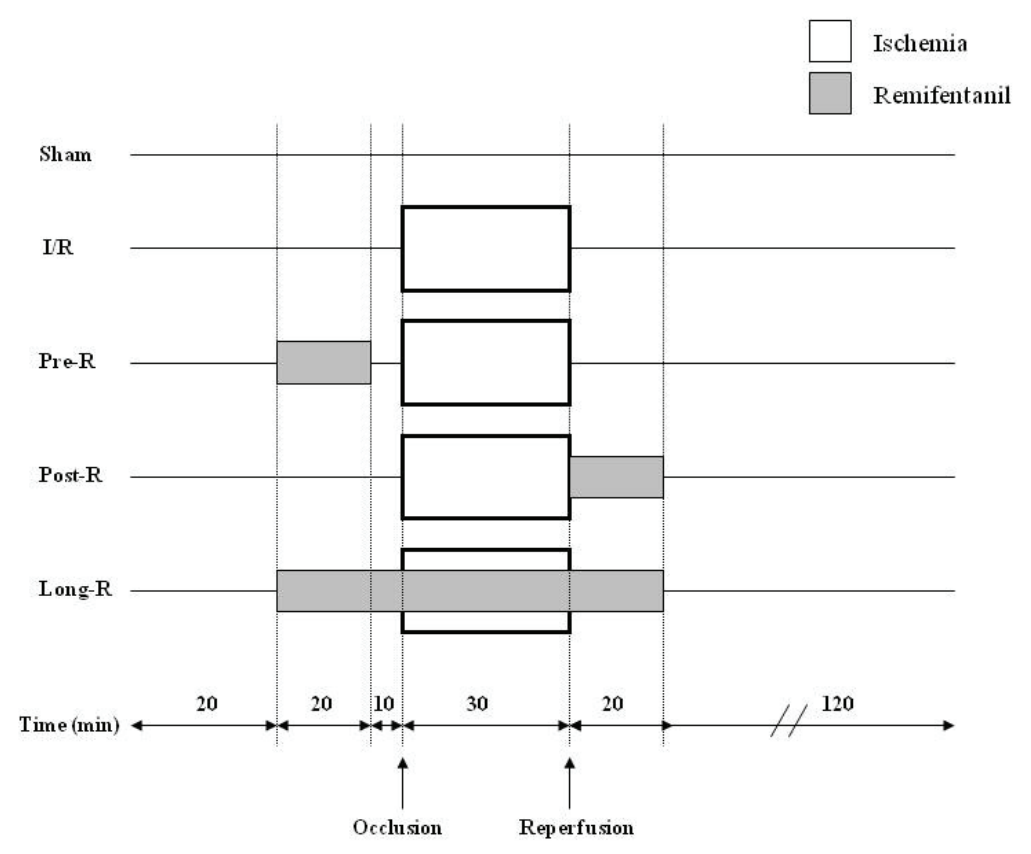

Fig. 1. The experimental protocol. Occlusion of the left anterior (LAD) coronary artery was maintained for 30 min, followed by reperfusion. After $2 \mathrm{~h}$, sampling was performed for infarct size, immunoblot and RT-PCR, respectively. Sham, the coronary suture was not tied, and remifentanil was not administered; I/R, ischemia/reperfusion group $(n=7)$; Pre-R, remifentanil administered during the preconditioning period $(n=6)$; Post-R, remifentanil administered during the first $20 \mathrm{~min}$ of reperfusion ( $n=7)$; Long-R, remifentanil administered during the entire period (from the preconditioning to the first $20 \mathrm{~min}$ of reperfusion) $(n=9)$.

\section{Immunoblot analysis}

At the end of the reperfusion period, tissue preparation was performed (Uecker et al. 2003). Briefly, LV specimens were pulverized and dissolved in lysis buffer (Cell signaling, USA). The solution was vigorously homogenized with Pyrex Potter-Elvehjem Tissue Grinders (BLD science, USA) and then centrifuged at $12,000 \times \mathrm{g}$ for $10 \mathrm{~min}$ at $4{ }^{\circ} \mathrm{C}$, and supernatant was transferred to a new tube and stored at $-70{ }^{\circ} \mathrm{C}$. Protein concentrations were determined using the Bradford protein assay kit (BioRad, USA). Proteins were separated in a $12 \%$ SDS-polyacrylamide gel and transferred to PVDF membrane (Millipore Co, USA). After blocking the membrane with Tris-buffered salineTween 20 (TBS-T, $0.1 \%$ Tween 20) containing $5 \%$ nonfat dried milk for $1 \mathrm{~h}$ at room temperature, membranes were washed twice with TBS-T and incubated with primary antibodies for $1 \mathrm{~h}$ at room temperature or for overnight at $4{ }^{\circ} \mathrm{C}$. The following primary antibodies were used: rabbit anti- extracellular signal-regulated kinases (ERK 1/2), mouse anti-phospho ERK 1/2, mouse antiB cell leukemia/lymphoma-2 (Bcl-2), mouse anticytochrome C (Santa Cruz Biotechnology, USA), rabbit anti-Bcl-2-associated X protein (Bax) (Assay Designs, USA) and mouse anti- $\beta$ actin antibodies (Sigma, USA). The membranes were washed three times with TBS-T for
$10 \mathrm{~min}$, and then incubated for $1 \mathrm{~h}$ at room temperature with horseradish peroxidase (HRP)-conjugated secondary antibodies. After extensive washing, the bands were detected by enhanced chemiluminescence (ECL) reagent (Santa Cruz Biotechnology, USA). $\beta$-actin gene was used as the standards for equal of the protein samples. The band intensities were quantified using a Photo-Image System (Molecular Dynamics, Sweden). Each experiment was performed at least three times.

\section{RT-PCR analysis}

At the end of the reperfusion period, tissue preparation was performed (Uecker et al. 2003). Briefly, LV samples were vigorously homogenized with Pyrex Potter-Elvehjem Tissue Grinders (BLD science, USA) in TRI Reagent (Sigma, USA). Total RNA was prepared by the UltraspectTM-II RNA system (Biotecx Laboratories, Inc., USA) and single-stranded cDNA was then synthesized from isolated total RNA by Avian Myeloblastosis virus (AMV) reverse transcriptase. A $20 \mu 1$ reverse transcription reaction mixture containing $1 \mu \mathrm{g}$ of total RNA, $1 \mathrm{X}$ reverse transcription buffer (10 mM Tris-HCl, pH 9.0, $50 \mathrm{mM} \mathrm{KCl,} 0.1 \%$ Triton X100), $1 \mathrm{mM}$ deoxynucleoside triphosphates (dNTPs), 0.5 unit of RNase inhibitor, $0.5 \mu \mathrm{g}$ of oligo (dT) 15 and 15 units of AMV reverse transcriptase were incubated at 
Table 1. The nucleotide sequence of all primer pairs for proteins related to $\mathrm{Ca}^{2+}$ homeostasis.

\begin{tabular}{|c|c|c|}
\hline Genes & Primer sequence & Size (bp) \\
\hline \multirow[t]{2}{*}{ L-type $\mathrm{Ca}^{2+}$-channel } & Sense: 5'-TGTCACGGTTGGGTAGTGAA-3' & 346 \\
\hline & Antisense: 5'-TTGAGGTGGAAGGGACTTTG-3' & \\
\hline \multirow[t]{2}{*}{ PMCAl } & Sense: 5'-TGCCTTGTTGGGATTTCTCT-3' & 351 \\
\hline & Antisense: 5'-CACTCTGGTTCTGGCTCTCC-3' & \\
\hline \multirow[t]{2}{*}{$N C X$} & Sense: $5^{\prime}$-TGTCTGCGATTGCTTGTCTC-3' & 364 \\
\hline & Antisense: 5'-TCACTCATCTCCACCAGACG-3' & \\
\hline \multirow[t]{2}{*}{ SERCA2a } & Sense: $5^{\prime}$-TCCATCTGCCTGTCCAT- ${ }^{\prime}$ & 196 \\
\hline & Antisense: 5'-GCGGTTACTCCAGTATTG-3' & \\
\hline \multirow[t]{2}{*}{ Phospholamban } & Sense: 5'-GCTGAGCTCCCAGACTTCAC-3' & 339 \\
\hline & Antisense: $5^{\prime}$-GCGACAGCTTGTCACAGAAG-3' & \\
\hline \multirow[t]{2}{*}{ Ryanodine receptor 2} & Sense: 5'-CCAACATGCCAGACCCTACT-3' & 351 \\
\hline & Antisense: $5^{\prime}$-ТTTCTCСАТССТСТСССТCA-3' & \\
\hline \multirow[t]{2}{*}{ Calsequestrin } & Sense: 5'-TCAAAGACCCACCCTACGTC-3' & 352 \\
\hline & Antisense: 5'-CCAGTCTTCCAGCTCCTCAG-3' & \\
\hline
\end{tabular}

Table 2. Hemodynamic parameters.

\begin{tabular}{llccccc}
\hline & \multicolumn{2}{c}{ Baseline } & \multicolumn{2}{c}{ Ischemia } & \multicolumn{2}{c}{ 2 h after reperfusion } \\
& HR & MAP & HR & MAP & HR & MAP \\
\hline I/R & $437 \pm 52$ & $131 \pm 14$ & $446 \pm 67$ & $127 \pm 17$ & $449 \pm 35$ & $129 \pm 15$ \\
Pre- $R$ & $456 \pm 47$ & $144 \pm 7$ & $467 \pm 57$ & $129 \pm 8$ & $462 \pm 48$ & $134 \pm 10$ \\
Post $R$ & $397 \pm 61$ & $129 \pm 10$ & $402 \pm 48$ & $132 \pm 9$ & $347 \pm 48^{*}$ & $118 \pm 15$ \\
Long- $R$ & $424 \pm 38$ & $135 \pm 11$ & $384 \pm 41$ & $101 \pm 6^{* *}$ & $345 \pm 40^{* * \dagger}$ & $99 \pm 25^{\dagger}$ \\
\hline
\end{tabular}

$\mathrm{HR}$, heart rate; MAP, mean arterial pressure; I/R, ischemia/reperfusion group ( $n=7)$; Pre- $\mathrm{R}$, remifentanil administered during the preconditioning period $(n=6)$; Post- $\mathrm{R}$, remifentanil administered during the first 20 min of reperfusion ( $n=7)$; Long- $\mathrm{R}$, remifentanil administered during the entire period (from the preconditioning to the first $20 \mathrm{~min}$ of reperfusion) ( $n=9$ ). Data are mean \pm SD. ${ }^{*} \mathrm{P}<0.05,{ }^{* *} \mathrm{P}<0.01$ vs. I/R group; ${ }^{\dagger} \mathrm{P}<0.05,{ }^{\ddagger} \mathrm{P}<0.01$ vs. baseline.

$42{ }^{\circ} \mathrm{C}$ for $15 \mathrm{~min}$, heated to $99{ }^{\circ} \mathrm{C}$ for $5 \mathrm{~min}$, and then incubated at $0-5{ }^{\circ} \mathrm{C}$ for $5 \mathrm{~min}$. All primer pairs for DNA sequencing of genes related to $\mathrm{Ca}^{2+}$ homeostasis are shown in Table 1 . The PCR condition was $94{ }^{\circ} \mathrm{C}$ for $3 \mathrm{~min}, 94{ }^{\circ} \mathrm{C}$ for $1 \mathrm{~min}, 41-49^{\circ} \mathrm{C}$ for $1 \mathrm{~min}$ and $72{ }^{\circ} \mathrm{C}$ for $2 \mathrm{~min}, 35$ cycles, with a final extension for $10 \mathrm{~min}$ at $72{ }^{\circ} \mathrm{C}$. GAPDH gene (primers 5'-accacagtccatgccatcac-3' and $5^{\prime}$-tccaccacctgttgctgta-3', $450 \mathrm{bp}$ ) was used as the internal standard. The signal intensity of the amplification product was analyzed using the UVlband software (UVltec, UK).

\section{Statistical analysis}

Data are presented as means \pm SD or means \pm SEM. Where results of blots and RT-PCR are shown, a representative experiment is depicted. Data analysis was performed with statistical software program Prism v3.0 (GraphPad Software, USA). Hemodynamics was analyzed using two-way analysis of variance (ANOVA) with Bonferroni post-hoc test for multiple comparisons if $F$ ratio was significant. Infarct sizes were analyzed between groups using ANOVA with Student-NewmanKeula post-hoc test for multiple comparisons. Statistical significance was defined as $P<0.05$ and $P<0.01$.

\section{Results}

\section{Hemodynamics}

The heart rate and mean arterial pressure are summarized in Table 2. The heart rates in the Post-R $(P<0.05)$ and Long-R groups $(P<0.01)$ were significantly lower compared to the $\mathrm{I} / \mathrm{R}$ group after reperfusion. The 
heart rate in the Long-R groups after reperfusion was also significantly lower compared to the baseline value $(P<0.05)$. The mean arterial pressures significantly decreased at the end of ischemia $(P<0.01)$ and after reperfusion $(P<0.05)$ compared to the baseline value in the Long-R groups. The other values of heart rate and mean arterial pressure revealed no significant differences in either inter- or intra-group comparisons.

\section{Infarct size measurement}

Mean infarct size of the LV in the $\mathrm{I} / \mathrm{R}$ group was $43.6(5.5) \%$. In the groups administered with remifentanil, infarct sizes of the LV were significantly reduced to 20.1 (1.9) \%, 18.8 (3.8) \% and 19.3 (3.2) \% in the Pre-R, Post-R and Long-R group, respectively (all $P<0.05)$. No significant differences were observed between the remifentanil-administered groups (Fig. 2).

Western blotting analysis on phosphorylation of ERK 1/2 and apoptosis related proteins

Phosphorylations of ERK 1/2 were significantly lower in the $I / R$ group than in the Sham group. Phosphorylations of ERK $1 / 2$ in the remifentaniladministered groups were significantly improved compared to the $\mathrm{I} / \mathrm{R}$ group, but were lower than in the Sham group. Phosphorylations of ERK 1/2 were similar between the remifentanil-administered groups (Fig. 3A).

Expression levels of pro-apoptotic proteins, Bax and cytochrome $\mathrm{c}$, significantly increased and expression level of anti-apoptotic protein, Bcl-2 significantly decreased in the $\mathrm{I} / \mathrm{R}$ group than in the Sham group. In the remifentanil-administered groups, the expression levels of Bax and cytochrome c significantly decreased and the expression level of Bcl-2 significantly increased than in the $\mathrm{I} / \mathrm{R}$ group. The expression levels of Bax, cytochrome $\mathrm{c}$ and $\mathrm{Bcl}-2$ were similar among the remifentaniladministered groups (Fig. 3B).

Gene expression of proteins influencing the calcium homeostasis

In the $\mathrm{I} / \mathrm{R}$ group, gene expression for sarcoplasmic reticulum (SR) proteins including SR $\mathrm{Ca}^{2+}$ ATPase (SERCA2a), phospholamban (PLB), ryanodine receptor 2 (RyR), and calsequestrin (CSQ) was reduced compared to Sham group. In remifentanil-administered groups, mRNA transcription levels for SR proteins were significantly up-regulated than in the $\mathrm{I} / \mathrm{R}$ group without differences between the groups. The $\mathrm{Ca}^{2+}$ entry across the membrane through L-type $\mathrm{Ca}^{2+}$ channels is balanced by the

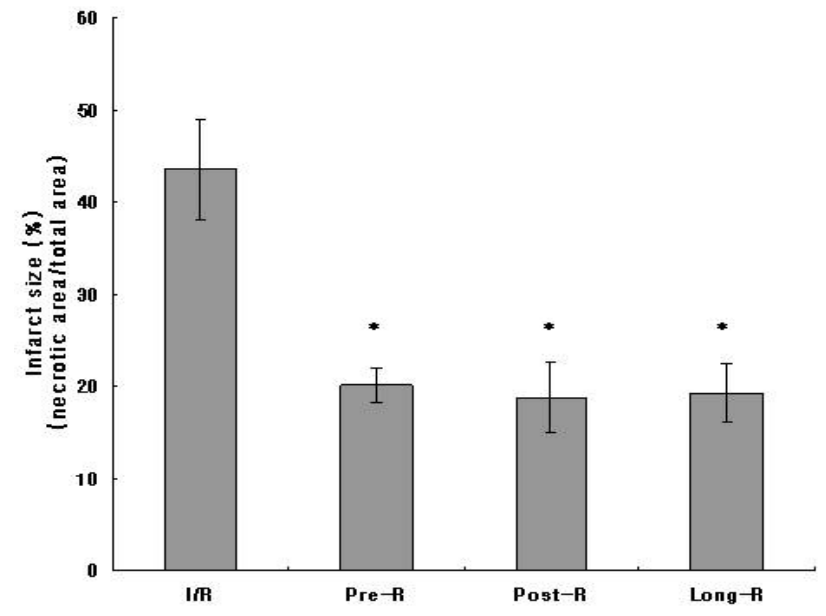

Fig. 2. Infarct sizes of the left ventricle in each group. Infarct size was expressed as a ratio of the left ventricular area. Values are presented as mean $\pm \mathrm{SEM} . * P<0.05$ compared with the I/R group ( $n=5-9$ per group).

efflux of $\mathrm{Ca}^{2+}$ from the cell via the $\mathrm{Na}^{+}-\mathrm{Ca}^{2+}$ exchanger (NCX) (Bers 2002). In the present results, levels of gene expression for L-type $\mathrm{Ca}^{2+}$ channels and NCX were unaltered by $\mathrm{I} / \mathrm{R}$ with or without remifentanil (Fig. 4).

\section{Discussion}

In the current study, remifentanil significantly reduced myocardial infarct size irrespective of the timing and duration of administration in $I / R$ rat heart, which occurred in conjunction with the preserved phosphorylations of ERK 1/2 and anti-apoptotic protein $\mathrm{Bcl} 2$ and attenuated increased pro-apoptotic proteins, Bax and cytochrome c resulting from I/R. Remifentanil administration also resulted in preserved gene expressions of SR proteins.

Remifentanil is a fentanyl derivative with a unique pharmacokinetic profile of rapid and predictable recovery, gaining increasing popularity in cardiac anesthesia. Similar to certain anesthetic agent, remifentanil has also been found to possess cardioprotective effects against $\mathrm{I} / \mathrm{R}$, although the effect occurred at significantly higher dose than that clinically used (Minto et al. 1997, Scott and Perry 2005). Remifentanil was reported to exert cardioprotective effect via all three opioid receptors (Peart and Gross 2004, Yu et al. 2007). Activation of $\kappa$ - and $\delta$ - opioid receptors was associated with activation of PKC and opening of mitochondrial $\mathrm{K}_{\mathrm{ATP}}$ channel, which are important targets of cardioprotection in ischemic and pharmacological preconditioning (Zhang et al. 2005). 
(A)
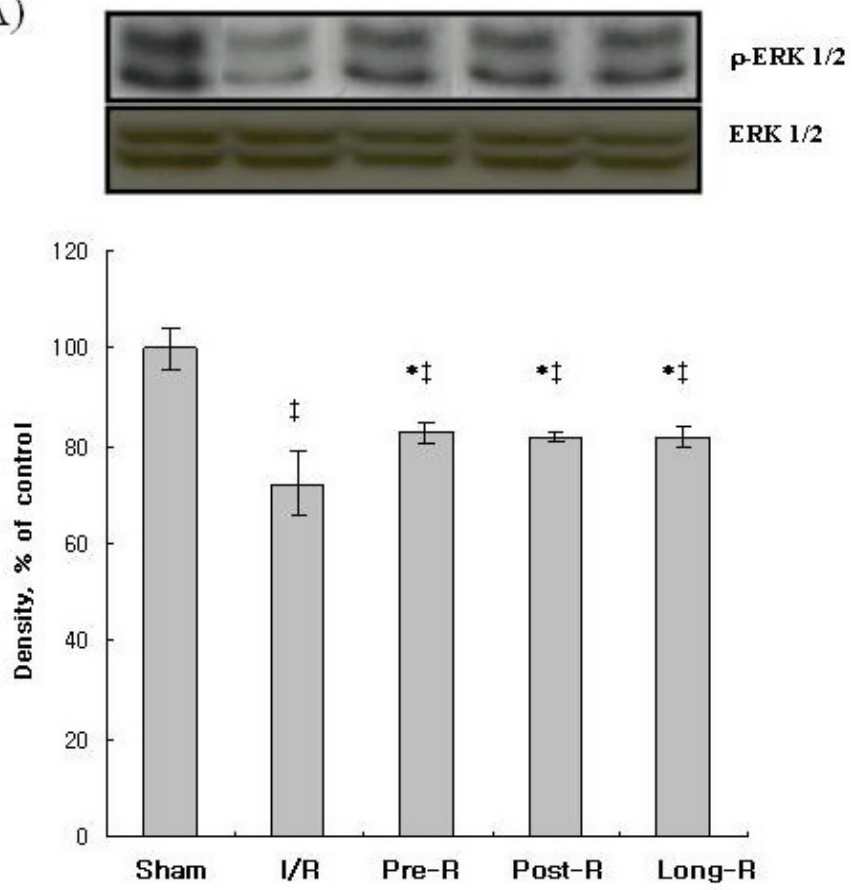

(B)
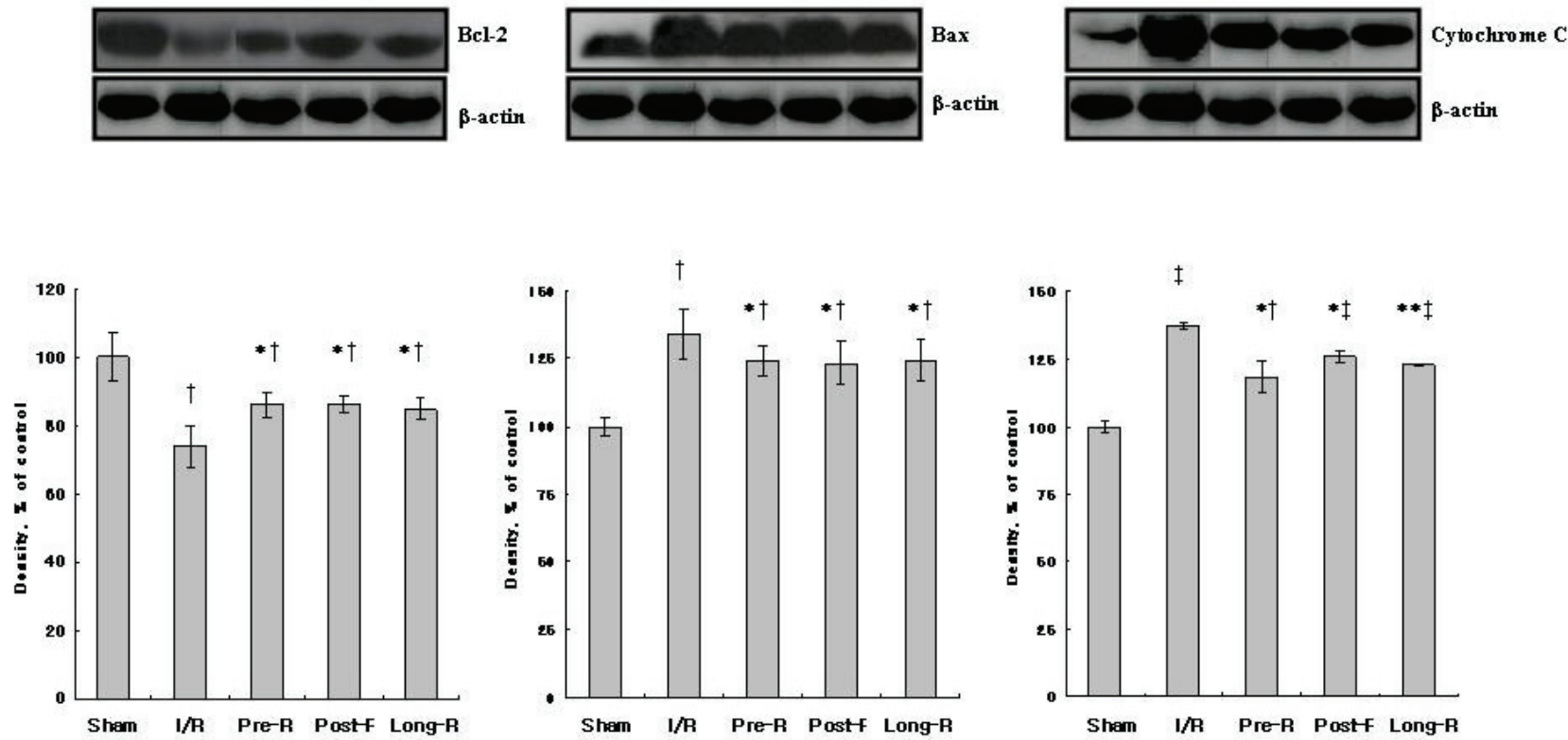

Fig. 3. Western blot analysis of (A) Western blot analysis of ERK $1 / 2$ and p-ERK $1 / 2$. (B) Western blot analysis of Bcl-2, Bax, and cytochrome c. Each signal was quantified by scanning densitometry. Values are presented as mean \pm SEM. $* P<0.05$ and $* * P<0.01$ compared with the I/R group.; $+P<0.05$ and $\neq P<0.01$ compared with the Sham group.

While other signal transduction pathways also play an important role in cardioprotection, however, little has been studied regarding mechanisms of remifentanil induced cardioprotection and we could observe that remifentanil acted through proteins involved in antiapoptoic pathways of survival regardless of timing and duration of administration. Apoptosis has been linked with reperfusion-induced myocardial injury after reversible coronary occlusion and suggested as one of the key mechanisms in the development of infraction in rat cardiac myocytes (Buja and Entman 1998, Haunstetter and Izumo 2000). 
(A)

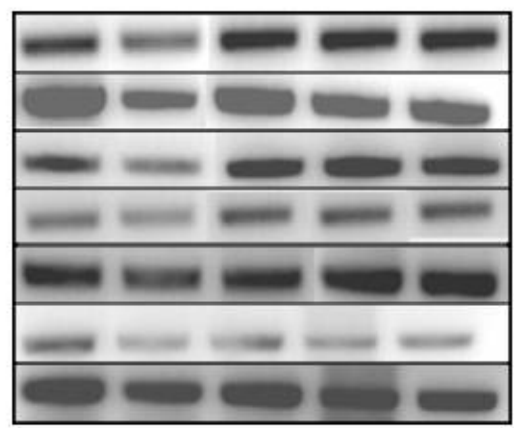

SERCA2a

Phospholamban

Ryanodine receptor 2

Calsequestrin

L-type $\mathrm{Ca}^{2+}$-channel

NCX

GAPDH

Sham I/R Pre-R Post-R Long-R

(B)

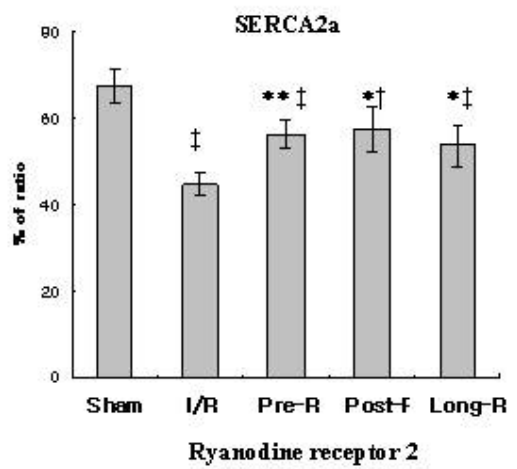

(D)

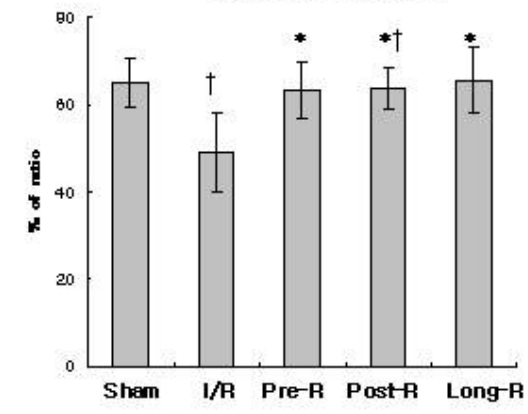

(F)

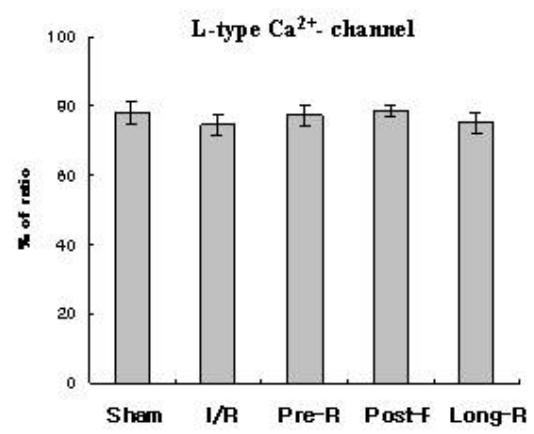

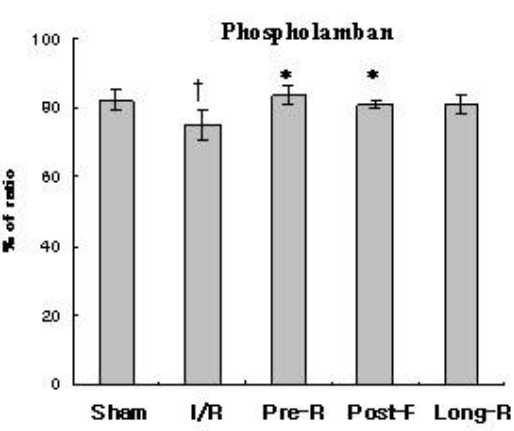

Calsequestrin
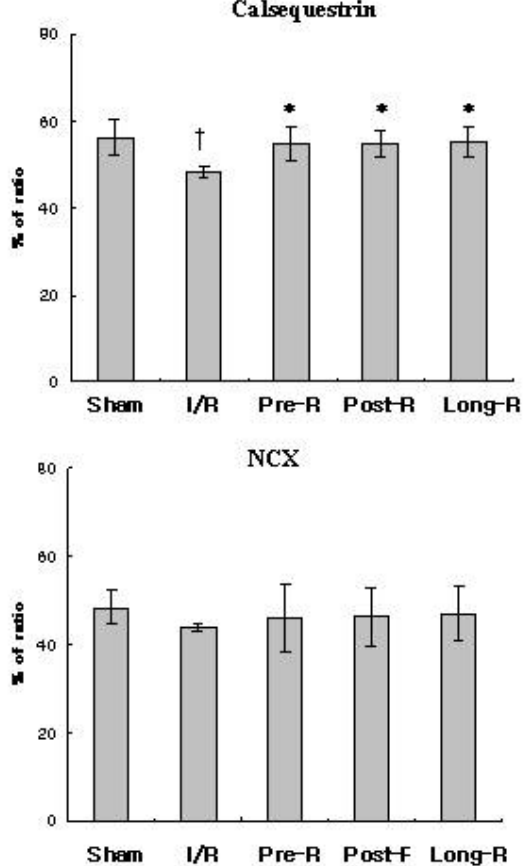

(E)

(C)

(G)

Fig. 4. Analysis of the expressions of genes related to $\mathrm{Ca}^{2+}$ homeostasis. (A) Representative gel image photographs of mRNA levels. (B-G) Histograms of SERCA2a (B), phospholamban (C), ryanodine receptor 2 (D), calsequestrin (E), L-type Ca ${ }^{2+}$-channel (F), and NCX (G). GAPDH was used as an internal standard. Each value is the mean \pm SEM of 5 hearts/group. $* P<0.05$ and $* * P<0.01$ compared with the I/R group; $+P<0.05$ and $\neq P<0.01$ compared with the Sham group.

In the current study, remifentanil increased the phosphorylation of ERK $1 / 2$ and anti-apoptotic proteins in $\mathrm{I} / \mathrm{R}$ rat heart. ERK is activated in response to $\mathrm{I} / \mathrm{R}$, oxidative stress, and hypoxia, and is an established player in the anti-apoptotic defense network (Yue et al. 2000).
As our results indicate, remifentanil preserved the phosphorylation of ERK $1 / 2$ which were significantly reduced following $\mathrm{I} / \mathrm{R}$ leading to improved viability of the rat heart exposed to $\mathrm{I} / \mathrm{R}$. In response to an apoptotic stimulus such as $\mathrm{I} / \mathrm{R}$, the pro-apoptotic protein, Bax, 
undergoes a conformational change that allows its translocation to the mitochondria, where it induces cytochrome c release. Phosphorylation of ERK 1/2 inhibits the conformational change in Bax protein and cytochrome c-induced caspase activation, thereby preventing apoptosis (Tsuruta et al. 2004). The antiapoptotic protein Bcl-2 attenuates cellular injury by inhibiting cytochrome c translocation (Kluck et al. 1997) and inhibits Bax translocation (Zhu et al. 2001). During ischemic preconditioning, an increase in $\mathrm{Bcl}-2$ in association with a decrease in the pro-apoptotic protein Bax occurred in isolated rat heart (Lazou et al. 2006). In this study, we could observe that improved phosphorylations of ERK1/2, and associated recovery of expression of Bcl-2 and mitigated expression of Bax and mitochondrial cytochrome $\mathrm{c}$ release against $\mathrm{I} / \mathrm{R}$ induced injury, which all indicate remifentanil induced a cardioprotective effect via anti-apoptosis pathways of survival in $\mathrm{I} / \mathrm{R}$ rat heart.

$\mathrm{Ca}^{2+}$ is an important messenger in intracellular signal transduction and the balance between Bcl-2 and Bax has been demonstrated to affect mitochondrial $\mathrm{Ca}^{2+}$ homeostasis, which is important in determining whether cells survive or undergo apoptosis. The SR plays a central role in regulating the intracellular $\mathrm{Ca}^{2+}$ concentration and contains SR $\mathrm{Ca}^{2+}$-cycling proteins such as RyR, SERCA2a, PLB, and CSQ. The expression of SR genes was significantly reduced in $\mathrm{I} / \mathrm{R}$ rat heart in this study. This was in accordance with the result of previous study (Temsah et al. 1999), and treatment with remifentanil preserved the levels of SR genes expression. These results suggest that remifentanil might modulate the expression of SR genes in I/R rat heart. Since we did not measure intracellular $\mathrm{Ca}^{2+}$ concentration, the real changes in intracellular $\mathrm{Ca}^{2+}$ concentration as consequences of remifentanil-induced modulation of $\mathrm{Ca}^{2+}$ homeostasis could not be clarified in this study.

With regard to the effect of timing and duration of drug administration on the extent of myocardial protection, the combination of pre- and postconditioning with sevoflurane provided additive cardioprotection (Obal et al. 2005), whereas desflurane showed no additive cardioprotective effects (Haelewyn et al. 2004). As we had investigated the cardioprotective effects of remifentanil with different administration protocols, we observed similar protective effect between remifentanil preconditioning and postconditioning groups, and could not observe additive cardioprotective effects in continuously administered group. These results suggest that cardioprotective signaling pathways may vary among anesthetics but activated pathways during remifentanil pre- and postconditioining might be similar, which merit further studies addressing the precise mechanisms of this particular anesthetic-induced cardioprotection.

Cardioprotective effects of remifentanil in this study were demonstrated at a dose of $6 \mu \mathrm{g} \mathrm{kg}^{-1} \mathrm{~min}^{-1}$ which is higher than the dose used in clinical practice (0.2-0.8 $\mu \mathrm{g} \mathrm{kg}^{-1} \mathrm{~min}^{-1}$ ) (Scott and Perry 2005). Previous studies reported that remifentanil had cardioprotective effect against I/R injury with dose-dependency, and the maximum effect of remifentanil was 6 or $10 \mu \mathrm{g} \mathrm{kg}^{-1} \mathrm{~min}^{-1}$ (Yu et al. 2007, Zhang et al. 2005). Based on those studies, we choose the minimal concentration of remifentanil inducing maximal cardioprotective effect. The pharmacological characteristics of remifentanil may vary and it is difficult to compare between species and can be given in relatively high doses for a short period of time (Yu et al. 2007, Zhang et al. 2005).

The limitation of this study is that we did not determine the area at risk. In this study, we referred the infarct size measurement to the methods of our research (Hwang et al. 2004, Kang et al. 2006). Therefore we determined the infarct size by dividing the total necrotic area by the total LV area. Although this method was used in other study (Bazargan et al. 2008), determining the necrotic area by the area at risk can be more accurate.

In conclusion, remifentanil confers myocardial protection against injury in $\mathrm{I} / \mathrm{R}$ rat heart without reference to the timing and duration of administration, which was conducted with preserved phosphorylations of ERK 1/2 and of signal transduction proteins against apoptotic cell death, and attenuated changes in expression of SR genes related to $\mathrm{Ca}^{2+}$ homeostasis.

\section{Conflict of Interest}

There is no conflict of interest.

\section{Acknowledgements}

This work was supported by the Brain Korea 21 Project for Medical Science, Yonsei University, Korea.

\section{References}

ANAYA-PRADO R, TOLENDO-PEREYRA LH: The molecular events underlying ischemia/reperfusion injury. Transplant Proc 34: 2518-2519, 2002. 
BAZARGAN M, FAGHIHI M, CHITSAZ M: Importance of timing of magnesium administration in the isolated ischemic-reperfused rat heart: role of $\mathrm{K}_{\mathrm{ATP}}$ channels. Physiol Res 57: 839-846, 2008.

BERS DM: Calcium and cardiac rhythms: physiological and pathophysiological. Circ Res 90: 14-17, 2002.

FLISS H, GATTINGER D: Apoptosis in ischemic and reperfused rat myocardium. Circ Res 79: 949-956, 1996.

GLASS PS: Remifentanil: a new opioid. J Clin Anesth 7: 558-563, 1995.

GOTTLIEB RA, ENGLER RL: Apoptosis in myocardial ischemia-reperfusion. Ann N Y Acad Sci 874: 412-426, 1999.

HAELEWYN B, ZHU L, HANOUZ JL, PERSEHAYE E, ROUSSEL S, DUCOURET P, GERARD JL: Cardioprotective effects of desflurane: effect of timing and duration of administration in rat myocardium. Br J Anaesth 92: 552-557, 2004.

HWANG KC, LIM S, KWON HM, BAE YS, KANG SM, CHUNG KH, GRAHAM RM, RHEE SG, JANG Y: Phospholipase C-deltal rescues intracellular $\mathrm{Ca}^{2+}$ overload in ischemic heart and hypoxic neonatal cardiomyocytes. J Steroid Biochem Mol Biol 91: 131-138, 2004.

KANG SM, LIM S, SONG H, CHANG W, LEE S, BAE SM, CHUNG JH, LEE H, KIM HG, YOON DH, KIM TW, JANG Y, SUNG JM, CHUNG NS, HWANG KC: Allopurinol modulates reactive oxygen species generation and $\mathrm{Ca}^{2+}$ overload in ischemia-reperfused heart and hypoxia- reoxygenated cardiomyocytes. Eur J Pharmacol 535: 212-219.

KLUCK RM, BOSSY-WETZEL E, GREEN DR, NEWMEYER DD: The release of cytochrome c from mitochondria: a primary site for Bcl-2 regulation of apoptosis. Science 275: 1132-1136, 1997.

LAZOU A, ILIODROMITIS EK, CIESLAK D, VOSKARIDES K, MOUSIKOS S, BOFILIS E, KREMASTINOS DT: Ischemic but not mechanical preconditioning attenuates ischemia/reperfusion induced myocardial apoptosis in anaesthetized rabbits: the role of Bcl-2 family proteins and ERK1/2. Apoptosis 11: 2195-2204, 2006.

MINTO CF, SCHNIDER TW, SHAFER SL: Pharmacokinetics and pharmacodynamics of remifentanil. Anesthesiology 86: 24-33, 1997.

MURRY CE, JENNINGS RB, REIMER KA: Preconditioning with ischemia: a delay of lethal cell injury in ischemic myocardium. Circulation 74: 1124-1136, 1986.

OBAL D, DETTWILER S, FAVOCCIA C, SCHARBATKE H, PRECKEL B, SCHLACK W: The influence of mitochondrial KATP-channels in the cardioprotection of preconditioning and postconditioning by sevoflurane in the rat in vivo. Anesth Analg 101: 1252-1260, 2005.

PATEL SS, SPENCER CM: Remifentanil. Drugs 52: 417-427, 1996.

PEART JN, GROSS ER, GROSS GJ: Opioid-induced preconditioning: recent advances and future perspectives. Vascul Pharmacol 42: 211-218, 2005.

PEART JN, GROSS GJ: Exogenous activation of delta- and kappa-opioid receptors affords cardioprotection in isolated murine heart. Basic Res Cardiol 99: 29-37, 2004.

SCHULTZ JE, GROSS GJ: Opioids and cardioprotection. Pharmacol Ther 89: 123-137, 2001.

SCOTT LJ, PERRY CM: Spotlight on remifentanil for general anaesthesia. CNS Drugs 19: 1069-1074, 2005.

TANAKA K, LUDWIG LM, KERSTEN JR, PAGEL PS, WARLTIER DC: Mechanisms of cardioprotection by volatile anesthetics. Anesthesiology 100: 707-721, 2004.

TEMSAH RM, NETTICADAN T, CHAPMAN D, TAKEDA S, MOCHIZUKI S, DHALLA NS: Alterations in sarcoplasmic reticulum function and gene expression in ischemic-reperfused rat heart. Am J Physiol 277: H584-H594, 1999.

TSURUTA F, MASUYAMA N, GOTOH Y: The phosphatidylinositol 3-kinase (PI3K)-Akt pathway suppresses Bax translocation to mitochondria. J Biol Chem 277: 14040-14047, 2002.

UECKER M, DA SILVA R, GRAMPP T, PASCH T, SCHAUB MC, ZAUGG M: Translocation of protein kinase C isoforms to subcellular targets in ischemic and anesthetic preconditioning. Anesthesiology 99: 138-147, 2003.

YU CK, LI YH, WONG GT, WONG TM, IRWIN MG: Remifentanil preconditioning confers delayed cardioprotection in the rat. Br J Anaesth 99: 632-638, 2007.

YUE TL, WANG C, GU JL, MA XL, KUMAR S, LEE JC, FEUERSTEIN GZ, THOMAS H, MALEEFF B, OHLSTEIN EH: Inhibition of extracellular signal-regulated kinase enhances ischemia/reoxygenation-induced apoptosis in cultured cardiac myocytes and exaggerates reperfusion injury in isolated perfused heart. Circ Res 86: 692-699, 2000. 
ZHANG Y, CHEN ZW, GIRWIN M, WONG TM: Remifentanil mimics cardioprotective effect of ischemic preconditioning via protein kinase $C$ activation in open chest of rats. Acta Pharmacol Sin 26: 546-550, 2005.

ZHANG Y, IRWIN MG, WONG TM: Remifentanil preconditioning protects against ischemic injury in the intact rat heart. Anesthesiology 101: 918-923, 2004.

ZHU L, YU Y, CHUA BH, HO YS, KUO TH: Regulation of sodium-calcium exchange and mitochondrial energetics by Bcl-2 in the heart of transgenic mice. J Mol Cell Cardiol 33: 2135-2144, 2001. 